\title{
Use of Dural Graft to Prevent Cerebrospinal Fluid (CSF) Leakage and its Effects on Medulla Spinalis: An Experimental Study
}

Hasan Emre Aydin ${ }^{1 *}$, Zuhtu Ozbek ${ }^{1}$, Dilek Burukoglu ${ }^{2}$, Murat Vural ${ }^{1}$, Ali Arslantas ${ }^{1}$, Tevfik Erhan Cosan $^{1}$ and Metin Ant Atasoy ${ }^{1}$

${ }^{1}$ Department of Neurosurgery, Osmangazi University Faculty of Medicine, Eskisehir, Turkey

2Department of Histology and Embriology, Osmangazi University Faculty of Medicine, Eskisehir, Turkey

*Corresponding author: Hasan Emre Aydin, Department of Neurosurgery, Osmangazi University Faculty of Medicine, Eskisehir, 26480, Turkey, Tel: +90(533)6374707; E-mail: dremreaydin@gmail.com

Rec date: Dec 17, 2014; Acc date: Dec 30, 2014; Pub date: Jan 01, 2015

Copyright: (c) 2015 Aydin HE, et al. This is an open-access article distributed under the terms of the Creative Commons Attribution License, which permits unrestricted use, distribution, and reproduction in any medium, provided the original author and source are credited.

\begin{abstract}
Introduction: Dural injuries are encountered generally as trauma, spinal tumor excision or postop complications. It is a major problem leads to cerebrospinal fluid leakage meningitis. The method used often in repair is applying the watertight suture to the damaged area with appropriate measures of fascia and dural grafts. The used grafts can be ranged as bovine pericardium, synthetic collagen matrices, fibrin tissue adhesive, vicryl, and polydioxanone graft. In the studies, it is observed that there is still no significant difference between grafts and fascia.
\end{abstract}

Material-Methods: In our study, 60 Spraque Dawley rats whose weights are ranging from 200-250 gr were used. The solution consists of the ketamine hydrochloride $(60 \mathrm{mg} / \mathrm{kg})$ and xylazine $(12 \mathrm{mg} / \mathrm{kg})$ was injected intraperitoneally to the subjects and the subjects were taken into anesthesia. The subjects were divided into 5 groups. In the first group no extra action was taken, in the second group, fibrin tissue adhesive was applied on the dural injury and in the third group collagen matrix was applied on the dural injury, in the fourth group bovine pericardium was applied on the dural injury, in the fifth group subcutaneous fascia (autogenetic graft) was applied on the dural injury.

Surgical Operation: After providing the sterile conditions and operating the anesthesia agents, the experimental animals were laid down on the operating table in the prone position for surgical operation. Following the local area cleaning and environment isolation, subcutaneous incision was applied. Fascia was opened and paravertebral muscles were scarred subperiostally. After applying L1-4 laminectomy, approximately $2 \mathrm{~cm}$ linear incision was made with bistoury and cerebrospinal fluid leakage was observed from the dural injury. Analgesia was applied with 10 $\mathrm{mg} / \mathrm{kg}$ paracetamol on the subjects which survived approximately 6 weeks after the operation. On the 7 th day (early group) after the operation, 6 animals from each group and 6 animals from each group after 6 weeks from the operation were injected $100 \mathrm{mg} / \mathrm{kg}$ phenobarbital intraperitoneally and scarification operation was completed. Former incision was opened and spinal cord under the laminectomy area was removed with the dural graft as a block and histopathological findings was provided.

Histopathological findings: The incisions from this area were stained with Hematoxylin Eosin and Masson Trichrome. In the examination, collagen, vascular diagenesis and necrosis from histopathological findings were examined in early period (first week) and late period (sixth) week. It was observed that in the groups.

Keywords: Cerebrospinal fluid leakage; Dural repair; Dural grafts; Spinal cord

\section{Introduction}

Dural injuries result typically from trauma, spinal tumor excision or postoperative complication [1]. Dural damage is a great problem which may cause serious complications like meningitis and delay in wound healing as well as cerebrospinal fluid leak [2,3]. Although appropriate method used commonly is to close watertightly the damaged area by the use of fascia or dural grafts at appropriate sizes, watertight suture closure may not be possible always depending on tumoral invasion or dural retraction [1].

Dural grafts used first by Campell and Sharkey in 1958 divide in two groups: heterogeneous and autogenous grafts [4,5]. Heterogeneous grafts are bovine pericardium, synthetic collagen matrix, fibrinogen glue, cadaveric dura, acellular human dermis allograft and vicryl or pds reinforced grafts [6,7]. These grafts are manufactured as pericardial, intestinal mucosal and peritoneal grafts in industry [8]. Autogenous grafts are taken commonly from fascia lata. In our study effects of grafts on peripheral tissues especially medulla spinalis in dura repair by using different heterogeneous grafts and auto grafts which are not determined yet to be superior to each other are discussed.

\section{Materials and Methods}

Confirmation of Osmangazi University, Medical Faculty Ethics Commitee was taken for the study. In our study 10-12 week old Sprague-Dawley rats weigthing 400 to 450 grams (TICAMOsmangazi University) were used. A general anesthesia was established with the intraperitoneal application of the appropriate-dose mixture of ketamine hydrochloride $(60 \mathrm{mg} / \mathrm{kg}$, Ketalar $500 \mathrm{mg}$ 
injectable 1 bottle, Pfizer, Turkey) and xylazine (12 mg/kg, Rompun $20 \mathrm{mg} / \mathrm{mL}$ injectable bottle, Bayer, Turkey) under the supervision of a veterinarian.

\section{Surgery}

Operation site was scrubbed with povidone iodine scrub (Medica brush; 4\% chlorhexidine soap, Medica BV, Netherlands) and disinfected by being painted with povidone iodine (Poviod; $10 \%$ polivinilpirrolidoniyod complex, Saba, Turkey) solution after rats are located in prone position on operation table. Operation site was covered with sterile covers. Sacroiliac crests were palpated and a skin incision was made over spinous processes at the midline from the level of thoracic (T) 9 vertebrae to the level of the level of lumbar (L) 2 vertebrae. Paraspinous muscles were separated using blunt dissection technique and T11-12 and L1-2 were visualized. And then 4 level laminectomy was performed under microscope (Opmi I, Carl Zeiss, Germany) with a high speed drill. Surgical site was uncovered by using automatic fascia retractors. Cerebrospinal fluid (CSF) leakage was seen with dura incision. After the application of fibrinogen glue to dura in second group, fascia was covered with $5 / 0$ vicryl and skin was sutured with silk suture $3 / 0$ and then surgical operation was completed. In other groups after observing cerebrospinal fluid (CSF) leakage upon dural incision self adhesive collagen matrix and bovine pericardium grafts were applied and then surgical operation was completed. Fascia lata was applied to fifth group with fibrinogen glue to damaged tissue. No surgical operation was performed in control group (Table 1). Single-dose cefazolin (50 $\mathrm{mg} / \mathrm{kg}$ ) (Cefazolin sodium, Mustafa Nevzat, Turkey) was applied intraperitoneally to subjects for prophylaxis. $10 \mathrm{mg} / \mathrm{kg}$ paracetamol (Perfalgan $10 \mathrm{mg} / \mathrm{mL}$ infusion, Bristol-Myers Squibb, Turkey) and analgesia were applied to the subjects surviving after six weeks. At the end of sixth week surgical site infection and CSF collection weren't observed in subjects.

\begin{tabular}{|l|l|}
\hline Groups & Graft \\
\hline I & No surgical operation \\
\hline II & Fibrinogen glue \\
\hline III & Collogen Matrix \\
\hline IV & Bovine Pericardium \\
\hline V & Fascia Lata \\
\hline
\end{tabular}

Table 1: Groups of the study.

\section{Histopathological findings}

Samples for histopathology were taken by diving all groups into two groups as early and late periods. Vertebral column was removed in block form so as to include laminectomy site by being taken into operation after 12 hours following early period surgical operation. Late period histological samples were taken at 6th week. Sections taken for observation were painted with Hematoxylin Eosin (H\&E). When the sections in control group were observed under optical microscope, membrane structures surrounding medulla spinalis and white matter structure and axons and myelin sheaths in this structure, neurons existing at anterior and posterior horns of gray matter are observed normal at different enlargements in early and late periods (Figure 1). In the group to which fascia graft was applied, structures of membrane and peripheral connective tissues of medulla spinalis and white matter structure and axons and myelin sheaths in this structure, eucromatic nucleus structures of multipolar motor neurons at anterior horn of gray matter, explicit nucleolus structure and central canal structure containing ependymal cells together with cell bodies are observed as similar to control group at different enlargements in the optical microscopic observation in early and late periods (Figure 2). In the group where bovine pericardium and collagen matrix are used, partial cellular infiltration was observed in the membrane structures and peripheral tissues surrounding medulla spinalis at different enlargements. In the anterior horn of gray matter necrotic areas were observed in the anterior horn of gray matter and axons and myelin sheaths in this structure were observed close to normal (Figure 3). In the group where fibrinogen glue was applied, membrane structures surrounding medulla spinalis, white matter structure and axons and myelin sheaths in this structure were observed close to normal. But in gray matter partial necrotic areas were observed. However specifically for fibrinogen glue congestion was observed in the medulla arteries (Figure 4).

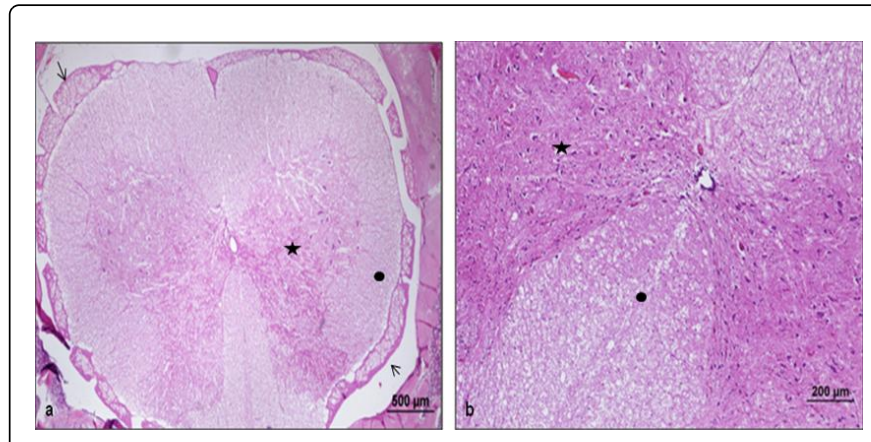

Figure 1: Membrane and peripheral connective tissues of medulla spinalis, white matter structure $(\bullet)$ and axons and myelin sheaths in this structure, gray matter structure $(*)$ and multipolar motor neurons and sense neurons in this structure, central canal structure containing ependymal cells $(\rightarrow)$ are observed close to normal at different enlargements under optical microscope (a-b) (bar: 500 $\mu \mathrm{m}$, bar: $200 \mu \mathrm{m}, \mathrm{HE})$.

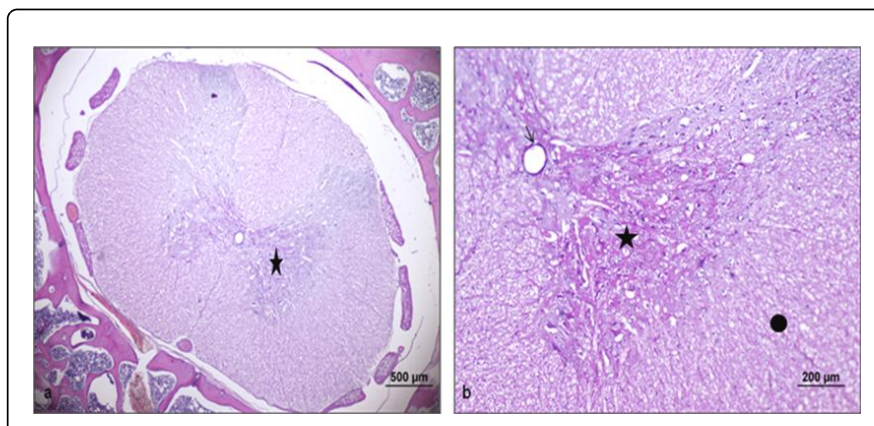

Figure 2: Membrane structures surrounding medulla spinalis $(\rightarrow)$, white matter structure $(\bullet)$ and axons and myelin sheaths in this structure, neurons in anterior and posterior horns of gray matter $\left({ }^{*}\right)$ are observed normal at different enlargements under optical microscope (a-b) (bar: $500 \mu \mathrm{m}$, bar: $200 \mu \mathrm{m}, \mathrm{HE})$. 


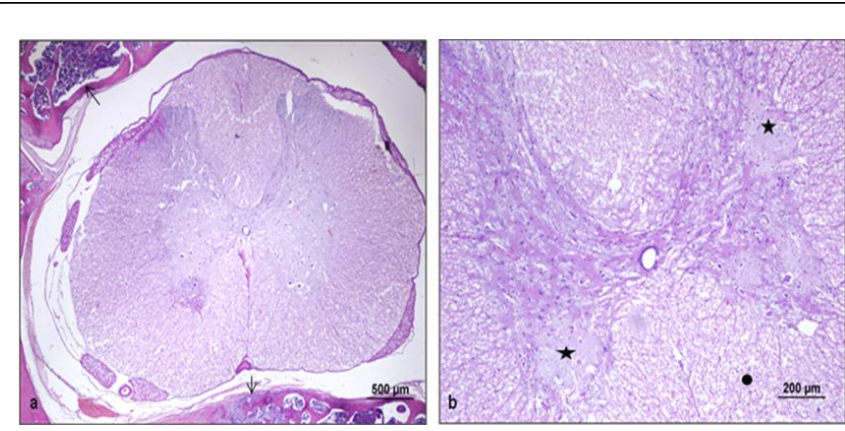

Figure 3: partial cellular infiltration $(\rightarrow)$ is observed in the membrane structures and peripheral tissues surrounding medulla spinalis at different enlargements. Necrotic areas are observed in anterior horn of gray matter $(*)$ and white matter structure $(\bullet)$ and axons and myelin sheaths in this structure are observed close to normal at different enlargements under optical microscope $(a-b)$ (bar: $500 \mu \mathrm{m}$, bar: $200 \mu \mathrm{m}, \mathrm{HE}$ ).
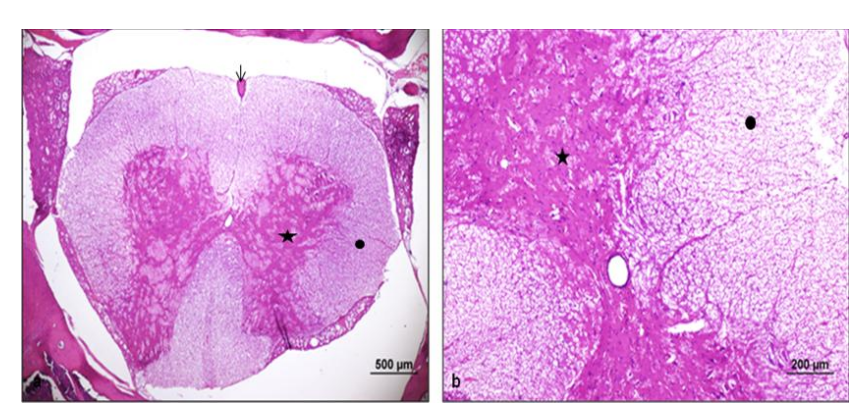

Figure 4: Membrane structures surrounding medulla spinalis, white matter structure $(\bullet)$ and axons and myelin sheaths in this structure are observed close to normal at different enlargements under optical microscope. But partial necrotic areas are observed in grey matter $(*)$. However congestion was observed in the medulla arteries $(\rightarrow)(\mathrm{a}-\mathrm{b})$ (bar: $500 \mu \mathrm{m}$, bar: $200 \mu \mathrm{m}, \mathrm{HE})$.

When the samples taken in early and late periods are examined, no reactional tissue or infection developing against the graft used in the subjects was observed.

\section{Statistical analysis}

Statistical analysis was performed by using the variables like necrosis, cellular inflammation and congestion on SPSS 18.0 and Simastat 3,5. No significant difference was found when the cellular changes in medulla spinalis are compared between the groups where graft is used and between the groups where graft is used and control group at the end of Kruskal-wallis and multiple comparison tests $(\mathrm{p}<0.05)$.

\section{Discussion}

Dura is a connective tissue consisting of collagen fibrils, fibroblasts and elastic fibrils and surrounding meningeal tissue. It is made up of three layers. Middle layer is made up of collagen, it is deprived of invervation but it is rich in vascular structures. Outer layer is thick and is made up of a few elastic fibrils. But inner layer consists of longitudinally oriented elastic fibrils. When considered generally, dura is a connective tissue consisting of longitudinally and cross sectionally oriented fibrils, micro fibrils and collagen [9]. Heterogeneous grafts are produced from active substances which are appropriate for normal structure like fibrin and collagen.

Dural grafts are used to prevent CSF leakage in case of dural damage and the adhesion between medulla spinalis and superior soft tissues and the contamination of infectious agents by establishing a barrier between them.

Fibrilles increase the adhesion in heterogeneous grafts and new dura formation is provocated with fibroblast proliferation and an effective barrier is established. Upon the presentation of autoregenerative feature of dura, absorbable heterogeneous grafts have started to be used commonly [10].

Dural damage occurs depending on trauma, tumor and spinal surgical procedures. Defects requiring duraplasty due to dural invasion occur especially in tumors. These defects should be repaired quickly since it starts with a clinically non-specific headache and it causes a disease like meningitis with high morbidity and mortality $[11,12]$. Dural damage is not appropriate for water-tight suture and requires auto-adhesive dural grafts in case of tumoral involvement and dural stress [8].

Fascia lata graft is preferred most commonly by surgeons as autogeneous graft. After a linear incision lateral to femur, graft is removed subcutaneously and skin is sutured. Possibility of the development of ache and infection during wound healing as well as cosmetic problems are significant problems in cosmetic use [11]. Since there is no significant difference between them and heterogeneous grafts, complications depending on taking fascia lata graft should be considered. Patient's preference should be prioritized in clinical practice by cosmetic reasons.

Tissue glue may be used in minor dural damages. Application of tissue glues which are sterile materials created with fibrinogen and thrombin especially to suture area is known to heal dural injury in $97 \%$ of cases and to prevent CSF leak [13,14].

Dura, muscle and occurring scar tissue were examined between heterogeneous grafts and fascia in the current studies and significant differences couldn't be found histopathologically between grafts in the studies where medulla spinalis sections are not considered. Heterogeneous dural grafts are the synthetic materials which cause fewer scars as compared with autogenous grafts and resist the CSF leak and infection risk [15].

Since heterogeneous dural grafts may be applied easily, they shortened surgical period [8]. Although autogenous grafts can't be accepted even by cosmetic reasons, positive results have been obtained from the use of dural graft [15]. Especially in the clinical studies performed using cattle pericardium which may be used in different areas like cardiovascular surgery they were shown to be grafts giving positive results $[16,17]$. In a series made recently it was seen that autologous pericranium $(\% 32)$, bovine pericardium $(\% 32)$, cadaveric dura $(\% 17)$, synthetic graft $(\% 16)$ and fascia lata graft $(\% 3)$ were used by surgeons [18].

\section{Conclusion}

In conclusion no significant difference is found between heterogen grafts as compared with auto graft at cellular level and heterogeneous 
Citation: $\quad$ Aydin HE, Ozbek Z, Burukoglu D, Vural M, Arslantas A, et al (2015) Use of Dural Graft to Prevent Cerebrospinal Fluid (CSF) Leakage and its Effects on Medulla Spinalis: An Experimental Study. J Neurol Disord 3: 202. doi:10.4172/2329-6895.1000202

Page 4 of 4

graft preference is left to surgeon in practice. Since there is no difference between existing grafts in early and late periods, all information about patients and disease should be considered and most appropriate graft should be selected for patient. Especially use of a different surgical section in clinical practice and complications which may develop in surgical site should be taken into consideration.

Considering the costs of use, since they may be used easily especially in the event that it is not possible to close watertightly, they cause fewer scars as compared with autogenous fascia graft, they are as resistant as autogenous graft to cerebrospinal fluid leak and infection risk and first and foremost they don't cause medulla spinalis adhesion, heterogeneous grafts may be preferred and fibrinogen glue may be preferred in minor defects.

\section{References}

1. Narotam PK, José S, Nathoo N, Taylon C, Vora Y (2004) Collagen matrix (DuraGen) in dural repair: analysis of a new modified technique. Spine (Phila Pa 1976) 29: 2861-2867.

2. Babuccu O, Kalayci M, Peksoy I, Kargi E, Cagavi F, et al. (2004) Effect of cerebrospinal fluid leakage on wound healing in flap surgery: histological evaluation. Pediatr Neurosurg 40: 101-106.

3. Barnes A, Cho G (1993) Basic fibroblast growth factor selectively amplifies the functional state of neurons producing neuropeptide $\mathrm{Y}$ but not somatostatin in cultures of fetal brain cells: evidence for a cooperative interaction with insulin-like growth factor-I. Endocrinology 133: 1895-1898.

4. Campbell JB, Bassett CA, Robertson JW (1958) Clinical use of freezedried human dura mater. J Neurosurg 15: 207-214.

5. Sharkey PC, Usher FC, Robertson RC, Pollard C Jr (1958) Lyophilized human dura mater as a dural substitute. J Neurosurg 15: 192-198.

6. Abla AA, Link T, Fusco D, Wilson DA, Sonntag VK (2010) Comparison of dural grafts in Chiari decompression surgery: Review of the literature. J Craniovertebr Junction Spine 1: 29-37.

7. Kashkouli MB (2007) A novel technique for small-incision fascia lata harvesting without a fasciatome for the frontalis suspension procedure. Orbit 26: 203-206
8. Costa BS, Cavalcanti-Mendes Gde A, Abreu MS, Sousa AA (2011) Clinical experience with a novel bovine collagen dura mater substitute. Arq Neuropsiquiatr 69: 217-220.

9. Vandenabeele F, Creemers J, Lambrichts I (1996) Ultrastructure of the human spinal arachnoid mater and dura mater. J Anat 189: 417-430.

10. Keller JT, Ongkiko CM Jr, Saunders MC, Mayfield FH, Dunsker SB (1984) Repair of spinal dural defects. An experimental study. J Neurosurg 60: $1022-1028$

11. Esposito F, Cappabianca P, Fusco M, Cavallo LM, Bani GG, et al. (2008) Collagen-only biomatrix as a novel dural substitute. Examination of the efficacy, safety and outcome: clinical experience on a series of 208 patients. Clin Neurol Neurosurg 110: 343-351.

12. Knopp U, Christmann F, Reusche E, Sepehrnia A (2005) A new collagen biomatrix of equine origin versus a cadaveric dura graft for the repair of dural defects--a comparative animal experimental study. Acta Neurochir (Wien) 147: 877-887.

13. Nagata K, Kawamoto S, Sashida J, Abe T, Mukasa A, et al. (1999) Meshand-glue technique to prevent leakage of cerebrospinal fluid after implantation of expanded polytetrafluoroethylene dura substitute-technical note. Neurol Med Chir (Tokyo) 39: 316-318.

14. Jankowitz BT, Atteberry DS, Gerszten PC, Karausky P, Cheng BC, et al. (2009) Effect of fibrin glue on the prevention of persistent cerebral spinal fluid leakage after incidental durotomy during lumbar spinal surgery. Eur Spine J 18: 1169-1174.

15. Takci E, Kadioglu HH, Bahceci H, Aydin IH (2001) The use of Dehydrated Human Dura mater grafts for the repair of the experimental cranial dural defects: Histopathologic Evaluation. J Turkish Neurosurg 11: 178-184

16. Baharuddin A, Go BT, Firdaus MN, Abdullah J (2002) Bovine pericardium for dural graft: clinical results in 22 patients. Clin Neurol Neurosurg 104: 342-344.

17. Anson JA, Marchand EP (1996) Bovine pericardium for dural grafts: clinical results in 35 patients. Neurosurgery 39: 764-768.

18. Haroun RI, Guarnieri M, Meadow JJ, Kraut M, Carson BS (2000) Current opinions fort he syringomyelia and chiari malformations: Survey of the Pediatric Section of the American Neurological Surgeons. Pediatr Neurosurg 33: 311-317. 